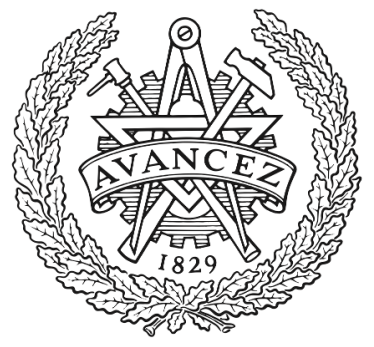

CHALMERS

UNIVERSITY OF TECHNOLOGY

\title{
Simple and Broadband Transition Between Rectangular Waveguide and Groove Gap Waveguide for mm-Wave Applications
}

Downloaded from: https://research.chalmers.se, 2023-04-26 10:34 UTC

Citation for the original published paper (version of record):

Vosoogh, A., Uz Zaman, A., Yang, J. (2018). Simple and Broadband Transition Between Rectangular Waveguide and Groove Gap Waveguide for mm-Wave Applications. IEEE Antennas and Propagation Society International Symposium: 1101-1102. http://dx.doi.org/10.1109/APUSNCURSINRSM.2018.8608176

N.B. When citing this work, cite the original published paper. 


\title{
Simple and Broadband Transition Between Rectangular Waveguide and Groove Gap Waveguide for mm-Wave Applications
}

\author{
Abbas Vosoogh, Ashraf Uz Zaman, and Jian Yang \\ Department of Electrical Engineering, Chalmers University of Technology, Gothenburg, Sweden \\ Emails: \{abbas.vosoogh; zaman; jian.yang\}@ chalmers.se
}

\begin{abstract}
A vertical wideband transition between a standard WR-15 rectangular waveguide (RW) and groove gap waveguide (GGW) in the V-band is presented. A simple step is applied to achieve a good impedance matching in transition between the RW and the GGW. A back-to-back transition is designed and fabricated to verify the simulation results. The measured results of the fabricated prototype show the insertion loss of less than $0.2 \mathrm{~dB}$ and the input reflection coefficient better than $-16 \mathrm{~dB}$ over almost the whole V-band (50-75 GHz).
\end{abstract}

\section{INTRODUCTION}

It has been shown that the gap waveguide technology has advantageous features and could be used as a low-loss guiding structure with simple mechanical assembly, especially at millimeter wave frequencies [1]. The gap waveguide concept is based on parallel-plate waveguide configuration, where a periodic electromagnetic bandgap (EBG) structure is used to control the direction of propagation without having leakage. Providing good electrical contact between different metal parts in complex hollow waveguide structures, such as corporate fed slot array antenna [2], is an expensive and complicated procedure, especially at higher frequencies. Tiny gaps between two metal blocks can cause huge leakage. On the other hand, multilayer structures can be designed based on the gap waveguide concept without the need of electrical contact requirement between the building blocks. In the gap waveguide concept, small gap among the building blocks is allowed, without having problem with leakage. Array antennas [3], [4], bandpass filters and diplexers [5] have been designed and reported based on gap waveguide technology, over the last few years. Since the interface of most equipments are standard RW, transitions from the new gap waveguide transmission lines to standard RW is needed. In [6] a vertical transition between inverted microstrip gap waveguide and WR-15 with $26.6 \%$ (56-73.3 GHz) relative bandwidth with reflection coefficient better than $-10 \mathrm{~dB}$ is obtained for the bach-to-back transition. In this paper, we propose a simple and wideband transition from GGW to RW with easy assembly to cover the whole V-band over the 50-75 GHz frequency band. The key features of the designed transition are the simplicity, easy assembly, low sensitivity to manufacturing and assembly errors, and wideband performance. Furthermore, the proposed transition is scalable and can be easily scaled to other frequency band.

\section{TRANSITION CONFIGURATION AND DESIGN}

The geometry of the proposed transition is shown in Fig. 1 The GGW line is formed in two separated metal plates, where a pin texture prevents any possible leakage. The two metal plates doesn't have electrical and galvanic contact. A simple step shaped metal piece at the end of the GGW line act as a $90^{\circ}$ E-plane bend to match the wave to standard WR-15

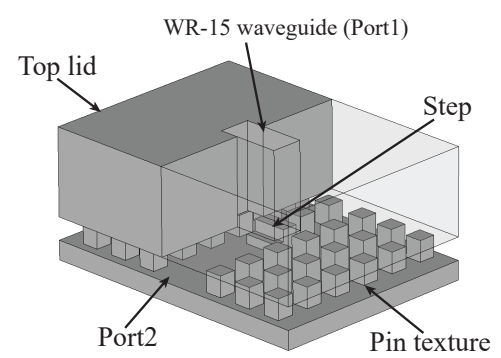

(a)

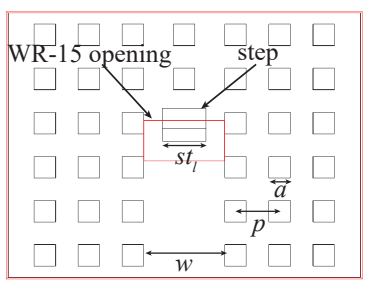

(b)

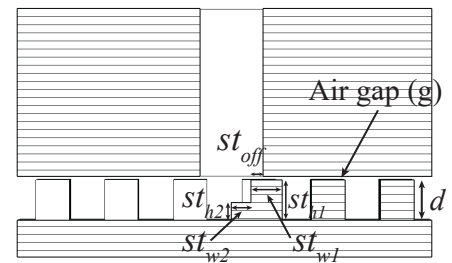

(c)
Fig. 1. Configuration of proposed GGW to RW transition. (a) 3-D view, (b) Top view, and (c) Side view.

TABLE I

DIMENSIONS OF THE PROPOSED TRANSITION (REFERS TO FIG. 11.

\begin{tabular}{|c|c|c|}
\hline Parameter & Value $(\mathrm{mm})$ & Description \\
\hline$w$ & 3.8 & GGW width \\
\hline$d$ & 1.2 & height of the pins \\
\hline$a$ & 1 & width of the pins \\
\hline$p$ & 2 & pins period \\
\hline$g$ & 0.1 & air gap \\
\hline$s t_{l}$ & 2 & length of the step \\
\hline$s t_{h 1}$ & 1.2 & height of the step1 \\
\hline$s t_{h 2}$ & 0.5 & height of the step2 \\
\hline$s t_{w 1}$ & 1 & width of the step1 \\
\hline$s t_{w 2}$ & 0.6 & width of the step2 \\
\hline$s t_{\text {off }}$ & 0.4 & step offset \\
\hline
\end{tabular}




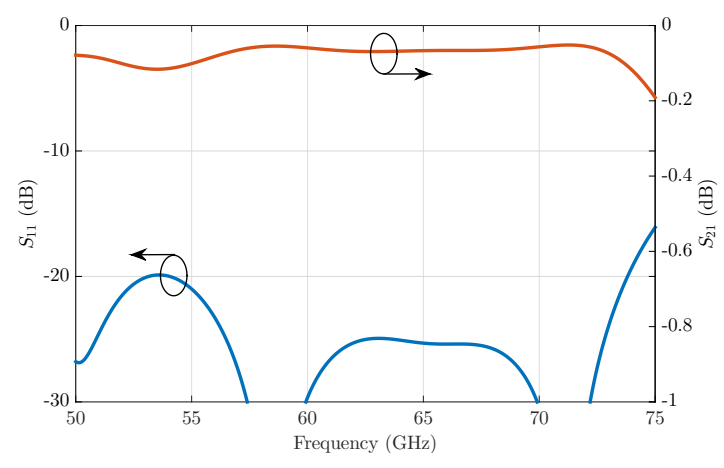

Fig. 2. Simulated S-parameters of single transition.

RW in the top lid. The dimensions and the position of the step is optimized in order to get good impedance matching. The transition geometrical parameters are presented in Table 1. The simulated S-parameters of the single transition is shown in Fig. 2 The simulation results are obtained by using CST Microwave Studio with aluminum as material of the transition. The designed transition shows good performance with the reflection coefficient bellow $-20 \mathrm{~dB}$ in almost all of the desired frequency band, except $-16 \mathrm{~dB}$ at $75 \mathrm{GHz}$. The average insertion loss is $-0.08 \mathrm{~dB}$.

\section{Measured Results}

A back-to-back transition is fabricated by Computerized Numerically Controlled (CNC) milling in aluminum, as shown in Fig. 3. To have a simple measurement setup and have enough space for WR-15 waveguide flanges, the ports are located at different metal plats. Therefore, one step transition is placed on the pin texture and one on the top metal plate.
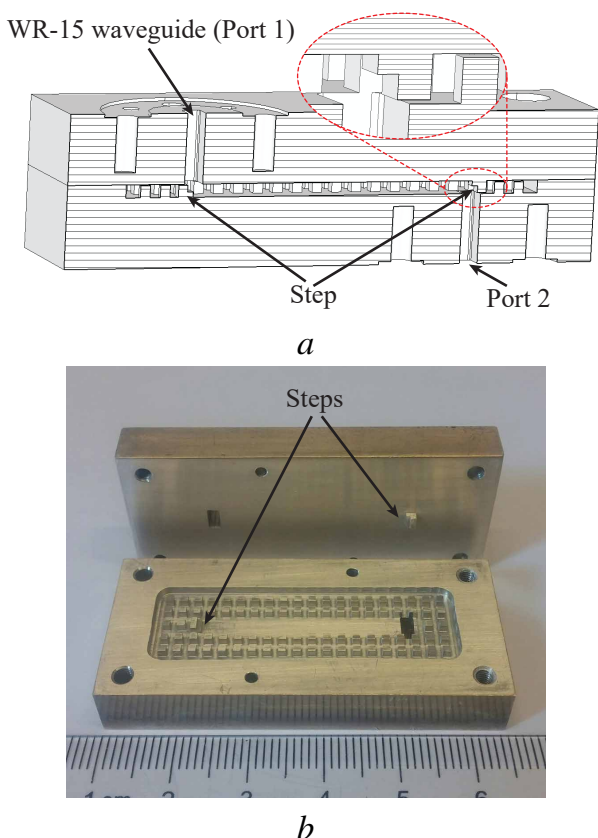

Fig. 3. Fabricated back-to-back GGW to RW transition. (a) side view, and (b) Photograph.

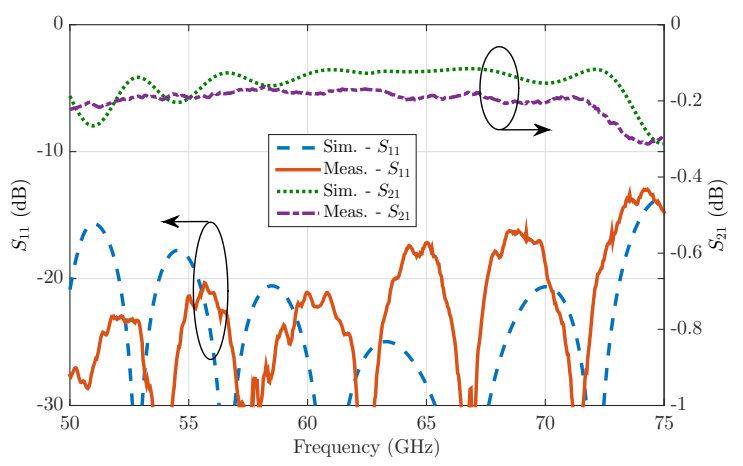

Fig. 4. Measured Simulated S-parameters of back-to-back transition.

This also shows the flexibility of the proposed transition. Fig. 4 shows the measured S-parameters in comparison with simulated results. Measurements for the back-to-back configuration show insertion loss lower than $0.2 \mathrm{~dB}$ and reflection coefficient better than $-16 \mathrm{~dB}$ from 50 to $75 \mathrm{GHz}$ frequency range. The measured and simulated results are in a good agreement, despite of a little higher insertion loss which is due to influence of higher surface roughness of the metal blocks.

\section{CONCLUSION}

We have presented a wideband vertical transition between GGW and RW in the V-band. The designed transition is compact and has a simple geometry with a very good input matching and low loss over a wide frequency band, which are demanding for future mm-Wave applications. This transition can be used as an interface between gap waveguide components, such as filters, diplexers, and planar array antennas to any device with standard waveguide flanges. The measured insertion loss for a back-to-back transition is less than $0.2 \mathrm{~dB}$ from 50 to $75 \mathrm{GHz}$, with relative bandwidth of $40 \%\left(\left|S_{11}\right|<-\right.$ $16 \mathrm{~dB}$ ). Even though the transition is designed at the V-band, it is easily scalable to other frequency band.

\section{REFERENCES}

[1] P.-S. Kildal, A. U. Zaman, E. Rajo-Iglesias, E. Alfonso, and A. ValeroNogueira, "Design and experimental verification of ridge gap waveguide in bed of nails for parallel-plate mode suppression," Microwaves, Antennas \& Propagation, IET, vol. 5, no. 3, pp. 262-270, 2011.

[2] T. Tomura, Y. Miura, M. Zhang, J. Hirokawa, and M. Ando, "A 45 linearly polarized hollow-waveguide corporate-feed slot array antenna in the 60GHz band," Antennas and Propagation, IEEE Transactions on, vol. 60, no. 8, pp. 3640-3646, 2012.

[3] A. Vosoogh, P.-S. Kildal, and V. Vassilev, "A multi-layer gap waveguide array antenna suitable for manufactured by die-sink EDM," in 2016 10th European Conference on Antennas and Propagation (EuCAP). IEEE, 2016, pp. 1-4.

[4] A. Vosoogh, M. S. Sorkherizi, A. U. Zaman, J. Yang, and A. A. Kishk, "An integrated Ka-band diplexer-antenna array module based on gap waveguide technology with simple mechanical assembly and no electrical contact requirements," IEEE Transactions on Microwave Theory and Techniques, 2017.

[5] M. Rezaee, A. U. Zaman, and P.-S. Kildal, "V-band groove gap waveguide diplexer," in Antennas and Propagation (EuCAP), 2015 9th European Conference on. IEEE, 2015, pp. 1-4.

[6] A. A. Brazález, E. Rajo-Iglesias, J. L. Vazquez-Roy, A. Vosoogh, and P.S. Kildal, "Design and validation of microstrip gap waveguides and their transitions to rectangular waveguide, for millimeter-wave applications," Microwave Theory and Techniques, IEEE Transactions on, vol. 63, no. 12, pp. 4035-4050, 2015. 